In fact to settle the age of the Cuddapahs-whether they are younger than or are the equivalent of the Delhis-is more important to the understanding of the pre-Cambrian stratigraphy of the Peninsula of India than to determine the absolute ages of the Archaean systems below the Delhis. And as the next province on my list for discussion happens to be Province No. 5-Rajputana-Gujarat-I should be extremely grateful to Professor Holmes, or to any other student of radio-active methods, if the answer to this question could be forthcoming quickly.

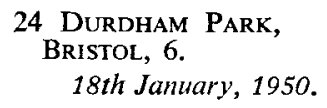

L. L. FERMOR.

\title{
OCEANIC MEANDERINGS
}

SIR,-D During the first world war the slogan used to be-Join the Army and see the World; Join the Air Force and see the Next. In the second war even ordinary citizens were allowed reasonable opportunities for extra tellural exploration. Now we are enjoying a lull during which various Air organizations have perfected the means of conveying a body around the world at high speed with unique opportunities for seeing nothing under conditions of considerable discomfort.

I have recently made such a journey around the world and, excluding my objectives which were a tour in Papua and a visit to Melbourne and New York, the scenic value of my trip was confined to a view from a great height of the Arabian desert, an eight-hour stop at Honolulu, and about two hours of the crossing from San Francisco to New York. For the rest, the solid world was obscured either by cloud, darkness, or oceans. The Pacific and Atlantic crossings were uneventful; the former took two days and was complicated by Saturday, 10th December repeating itself, the latter only five and a half hours - thanks to a 150-mile an hour tail wind at 20,000 feetbut even these were hours of darkness.

These immense oceans have an irresistible fascination and as the aircraft winged its way above the deep blue expanse bending out of sight beyond the curving horizons, one pondered on their significance and past history. I, personally, like so many of us have been through the early enthusiasms for the Wegener hypothesis and have come out at the other side. To my mind there is no acceptable case for the Atlantic and Indian Oceans being other than submerged sectors of a once continuous continental mass though traversed by geosynclines and orogenic systems of various ages with a pattern comparable to that of the present land areas. The Pacific is less simple but, even in this case, if we free our minds from prejudice and take stock of the evidence critically there are many geological pointers to this great ocean being a foundered area of ordinary continental character, perhaps traversed by fold systems and certainly subject to undulations of the ocean bottom on a large scale.

I write this letter not to expound and document my present point of view but to call attention to a considerable body of new evidence which is accumulating on the problems of oceans. The basis of the theory of the permanence of oceans, including the Pacific, is being badly shaken and the time is coming for a new stocktaking with many new facts and changed ideas to work on.

The hypothesis of permanence of oceans is founded partly in very insecure geological speculation and partly on the geophysical deduction that there is an essential difference between continents and oceans, thereby erecting the sialsima fantasy. Geologists have been reluctant to admit that fold systems, and therefore their flanking continents, can continue into the oceans beyond the last point seen; if Fiji, for example, had not chosen to exhibit itself the 
western margin of the Pacific would have been accepted as close to the New Zealand-New Caledonia line. The history of the Rockies geosyncline throughout the Palaeozoic and Mesozoic indicates the former existence of a western continent and continental massifs are still exposed on the western flank of the orogen, the Chiapas massif in Mexico, for example.

The relationship between elevation of mountains and the effects of compression in the production of thrust and folded zones requires much more study than it is normally given. Is the elevation of a compressed zone a necessary sequel? We know that most mountain zones owe their present elevation to a broad up-warp subsequent to the compressive forces but perhaps in some cases the last phase may be of depression, as in certain zones of the East Indies. The great elevation of Greenland, and of the great Hawaian chain rising out of the Pacific, have the physical dimensions of Alpine zones but in neither case have we evidence of compressive forces.

The geophysical case for permanent oceans is based on gravity and seismic observations. It has been thought that gravitationally the oceans are different from the continents in having more uniform values dominantly positive but as more and more data accumulate this simple deduction is found not to hold. G. P. Woollard has recently published an important analysis of gravity values around the world and his conclusion is that "No sweeping statements can be made concerning any universal difference between the crust beneath the oceans and the continents from gravity data alone" (Trans. Amer. Geoph. Union, 30,1949, p. 200). As gravity evidence accumulates more and more holes are found in that convenient basket for geological loose thinking named isostasy and this also may have to go into discard.

The seismic evidence in the past has indicated that the deep oceans lack a crust of continental character but this sweeping generalization may require modification. As samples of recent work I might quote the results obtained by B. C. Browne and his colleagues at one of the Atlantic Ocean Weather Ships ( $53^{\circ} 51^{1} \mathrm{~N} ., 18^{\circ} 40^{1} \mathrm{~W}$.) where below a depth of water of 1,300 fathoms and 18,000 feet of low and medium velocity layers, presumably sediments, there was found a floor with a velocity of $21,000 \mathrm{ft}$. $/ \mathrm{sec}$. This is average continental basement velocity-and could even be massive limestone. Another sample from the Pacific is from Bikini where H. S. Ladd and J. I. Tracey obtained a velocity $17,000 \mathrm{ft}$./ $/ \mathrm{sec}$. at about $10,000 \mathrm{ft}$. depth (Sci. Monthly, Nov., 1949) which they regard as basement, but if so it is basement of a continental character or alternatively it might still be sediments.

Evidence of the physical relief and composition of the ocean bottoms is also accumulating. S. J. Shand (Journ. Geol., 57, 1949) has examined rock samples from the mid-Atlantic Ridge and found strong evidence (mylonitized anorthositic gabbro) of shearing stresses during or after the formation of the Ridge. The relief of the Atlantic bottom has been found to be as varied as that across the average continent. In the Pacific recent discoveries of "sea mounts" have been described by F. P. Shepard (Submarine Geology, 1948). These are plateau topped protuberances from the deep ocean floor at depths below present surface of 500 to 600 fathoms and suggestive of erosion surfaces. The evidence of both submarine canyons and these sea-mounts points to a marked relative subsidence of the ocean bottom in certain areas in recent geological time.

These are somewhat random thoughts, perhaps insufficiently developed, provoked by my journey and by a study of recent literature. I have set them down in order to call attention to the unsatisfying state of many existing geological ideas and to stimulate a more critical approach.

BRITANNIC House,

LONDON, E.C. 2 .

G. M. LEES.

31st January, 1950. 